\title{
Perceptions of shellfish aquaculture in British Columbia and implications for well-being in marine social-ecological systems
}

\author{
Linda M. D'Anna ${ }^{1}$ and Grant D. Murray ${ }^{1}$
}

\begin{abstract}
Shellfish aquaculture is often positioned as an adaptive alternative to traditional resource industries, but the social and cultural effects of expanding production on coastal/marine social-ecological systems are unclear. Reporting on a multimethods study, we present perceptions about shellfish aquaculture collected through interviews, participant-employed photography, and a household survey in British Columbia, Canada. With an approach focused on local preferences for social-ecological conditions and the ways in which those conditions may be enhanced or diminished, we indicate that perceptions of the effects of aquaculture on the environment, economy, and lived experience are composed of both objective and subjective components. Interview responses and survey opinions varied widely and included bimodal responses. Industry interviewees tended to focus on environmental and economic benefits while acknowledging concerns about the environment and lived experience. Nonindustry interviewees typically questioned the environmental effects while underscoring economic benefits and negative effects on experience. Most survey participants felt positively about the effects on the economy, expressed negativity and uncertainty about effects on the environment, and demonstrated the greatest variability in opinions about effects on lived experience. Findings revealed uncertainty and alienation across all dimensions. Our findings, used as an analytical lens, support the usefulness of the concept of well-being in attempts like this one to understand the dynamics of coastal communities by providing a framework for deciphering what is important to individuals and societies experiencing change and considering adaptations.
\end{abstract}

Key Words: coastal communities; marine; shellfish aquaculture; social-ecological systems; well-being

\section{INTRODUCTION}

Coastal and ocean ecosystems are experiencing a diverse array of pressures and are changing in unprecedented ways (Worm et al. 2006, Crain et al. 2009, Hoegh-Guldberg and Bruno 2010, Poloczanska et al. 2013). These changes threaten the continued provision of marine ecosystem services that support coastal communities, and adaptation and transformation may be essential to sustaining coastal social-ecological systems (SESs; MEA 2005, Folke et al. 2010, Barbier et al. 2011).

Aquaculture is often positioned as an adaptation to changing circumstances for its potential as an industry to address declines in wild capture fisheries, rising demands for seafood protein, and needed economic opportunities (Tidwell and Allen 2001). Global aquaculture production for food fish expanded by roughly 12 times from 1980 to 2012 to reach 66.6 million tonnes per year, and it currently accounts for approximately half of all fish produced for human consumption (FAO 2014). Aquaculture is also heavily promoted as an opportunity to strengthen the economic viability of isolated coastal areas by creating employment for young people, generating income for women, and improving access to food. Indeed, worldwide, fish farming is adding jobs at an annual rate of $5.5 \%$ compared to just $0.8 \%$ for wild capture fisheries (FAO 2014).

Within the aquaculture industry, molluscan or shellfish aquaculture is viewed as a particularly attractive adaptation to coastal change and is positioned as a "green" industry (Shumway et al. 2003, NRC 2010). However, although low social carrying capacity of targeted coastal areas has been recognized as a limiting factor in the adoption and expansion of shellfish aquaculture (Gibbs 2009), there has been limited research on the social and cultural effects of the industry (cf. Mazur and Curtis
2006, Pierce and McKay 2008, Joyce and Satterfield 2010, Byron et al. 2011, Rudell 2012, Silver 2013). We contribute to efforts to address this gap by identifying and measuring subjective views or perceptions about shellfish aquaculture and its effects among residents, including both those associated with the industry and those not associated with it, of a region of British Columbia, Canada, with a highly productive industry.

We consider how the perceived environmental, economic, and experiential effects of shellfish aquaculture have implications for the well-being of the social component in an SES. Although the Millennium Ecosystem Assessment (MEA 2005) was one of the first efforts to move beyond material benefits to frame well-being largely in terms of individual needs, recent scholarship suggests that a more socially defined conception of well-being is needed to capture the entirety of the environment-well-being relationship (McGregor 2008, Coulthard et al. 2011, Armitage et al. 2012, Coulthard 2012). We adopt the definition of well-being set forth by McGregor (2008:1): "Well-being is a state of being with others, where human needs are met, where one can act meaningfully to pursue one's goals, and where one enjoys a satisfactory quality of life." By not explicitly defining well-being, this definition demonstrates that what contributes to well-being is contextually dependent (Coulthard et al. 2011). This definition of well-being nests individual needs within broader social and cultural requirements such that the objective circumstances of a person and subjective evaluation of those circumstances are socially and culturally constructed through relationships (Coulthard et al. 2011). Our focus is on this subjective evaluation. The subjective dimension of well-being makes a valuable addition to efforts to understand the dynamics of coastal communities by unpacking what is important to individuals and society (Weerantunge et al. 2014) in choices about how to utilize, develop, or conserve natural 
resources. We present the results of a multimethod approach that draws on this understanding of well-being to illuminate the perceived effects of shellfish aquaculture on local communities.

\section{BACKGROUND AND STUDY SITE}

\section{Study site}

The study was conducted in the Baynes Sound area of the east coast of Vancouver Island, British Columbia (Fig. 1). Baynes Sound is an 8700 ha shallow coastal channel bordered by Vancouver Island to the east and Denman Island to the west. We confined our consideration of Baynes Sound to the area extending from an imaginary line connecting the community of Royston on Vancouver Island and the northern-most island of Sandy Island Marine Park off the north end of Denman Island to a second imaginary line connecting the community of Bowser on Vancouver Island and Chrome Island off the southern tip of Denman Island. The 2011 Canadian census recorded 6519 residents in the 8 communities in the study area, i.e., Bowser, Deep Bay, Mud Bay, Fanny Bay, Buckley Bay, Union Bay, Royston, and Denman Island, with $8 \%$ of the population employed in resource industries, i.e., agriculture, forestry, fishing, and hunting (CVRGS 2009). Construction, tourism, and retirement in-migration are key economic drivers for the region (CVRGS 2009).

Fig. 1. Map of the Baynes Sound area. The location and extent of shellfish farms are shown in green.

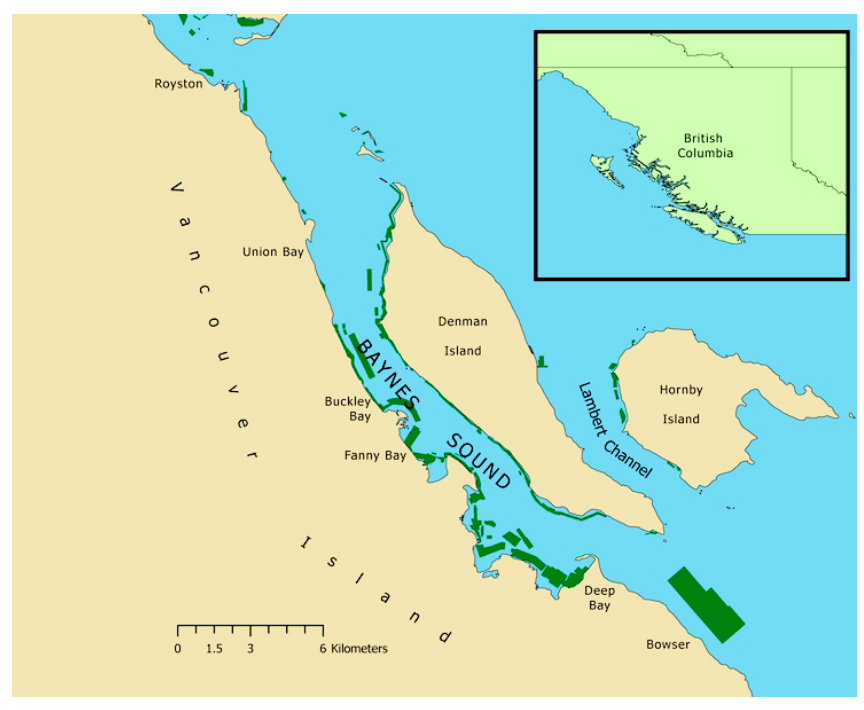

We focused on Baynes Sound because shellfish farming has been present in the area for nearly 100 years, and the area has transitioned away from other forms of resource extraction, i.e., logging and fishing. Because the industry is well established, we could document its effects to predict impacts it might have in communities considering shellfish aquaculture as an adaptive response to change.

\section{The British Columbia shellfish aquaculture context}

Canadian aquaculture production has experienced broad growth since the 1980s, and projections suggest production could double by 2020 (Olin et al. 2011). British Columbia accounts for more than half of the production in Canada's more than Can $\$ 1$ billion aquaculture industry (DFO 2013) and $22 \%$ of its shellfish aquaculture production (Olin et al. 2011). Shellfish aquaculture production in British Columbia is valued at Can $\$ 41$ million, i.e., the aggregate value of final products sold into the wholesale market (DFO 2013). The industry created Can $\$ 55.7$ million in wages and salaries in the province in 2011 (Stroomer and Wilson 2013).

Shellfish aquaculture has a long history in Baynes Sound dating back to the early 1900s as one of the first 2 sites in British Columbia where the Pacific oyster (Crassostrea gigas) was introduced from Japan for cultivation (Quayle 1988). Its more recent history has been marked by shifts in technology and intensity (Carswell et al. 2006) as well as conflict with other resource user groups and stakeholders regarding expansion (Hamouda et al. 2004). The sound is the most significant area in British Columbia for shellfish aquaculture, producing half of all the shellfish cultured in the province (BCMSRM 2002). Baynes Sound is the site of 129 shellfish aquaculture licenses covering a tenure area of 1157 ha (British Columbia Ministry of Environment [BC MoE], unpublished data). Note that ministry statistics for Baynes Sound include production and license sites in Lambert Channel and Comox Harbour; however, we did not extend our research to these areas. Carswell et al. (2006) determined that tenures occupy $20.3 \%$ of the intertidal area in the sound. Pacific oysters and manila clams (Venerupis philippinarum), both introduced species, make up the majority of the production on primarily beach and off-bottom sites. Baynes Sound produced 3762 tonnes of shellfish with a farm gate value of Can\$7.08 million in 2008 (BC MoE, unpublished data). There are 5 shellfish processing plants in the area that both hold shellfish tenures and process shellfish from farms within and outside of the sound.

In interpreting the results, it also important to briefly outline the socio-political context in which the industry is embedded and understood. Promoted for its purported capacities to enhance economic development in rural areas and contribute to sustainable global seafood production, the development and expansion of a tenured system of shellfish production in British Columbia has not been without conflict. For example, competition for sea space and the reduction of productive beach area for wild shellfish harvest have been cited as negative outcomes of the growth of shellfish aquaculture (Joyce and Canessa 2009, Joyce and Satterfield 2010). Others have suggested that the market-based paradigm of shellfish aquaculture pursued by the provincial and federal governments has often been incompatible with the more community-based approaches found at the local and regional levels (Pinkerton and Silver 2011). Likewise, the privatization of sea space, seen as a prerequisite for shellfish aquaculture development, has had critical implications for the collective rights practiced by First Nations (Silver 2013, 2014). Long under provincial oversight, at the end of 2010, Fisheries and Oceans Canada (DFO), the federal agency in charge of managing fisheries and protecting waters, assumed responsibility for regulating and managing the aquaculture industry in British Columbia, which includes licensing sites, establishing license conditions, and enforcing regulations. The province continued to issue tenures for aquaculture operations and regulate business aspects such as workplace health and safety. 


\section{METHODS}

We conducted a multimethods study consisting of interviews, participant-employed photography, and a household survey. We conducted 18 targeted interviews with Baynes Sound residents to identify local shellfish aquaculture issues. We interviewed 6 individuals who were directly involved in aquaculture as shellfish farm leaseholders or owners/managers of processing houses. We refer to these individuals as industry interviewees. We also interviewed 12 individuals who did not participate in the industry. This group of nonindustry interviewees was composed of property owners who live upland of shellfish farms, individuals involved with environmental and civic groups, and resource managers/government agents. The primary purpose of the interviews was not to provide a comparison of the views of these 2 interviewee categories but to indicate thematic categories of impact on well-being. There were 11 male and 7 female interviewees ranging in age from early 30 s to near 80 . One interviewee was a member of a First Nation; all others were of European decent. The semistructured interview guide included open-ended questions informed by our review of the literature on well-being on 5 general topics: (1) environment and ecology of Baynes Sound, (2) human communities of Baynes Sound, (3) ecological and social changes or concerns, (4) benefits and negative impacts of shellfish aquaculture, and (5) planning and decision making related to shellfish aquaculture.

Ten interviewees, including 2 industry interviewees, also engaged in a participant-employed photography component. All interview participants were invited to participate, but not all chose to do so. Participants submitted 5 photographs that captured what they like or are drawn to in the Baynes Sound environment and/or community and 5 photographs that illustrated concerns they have for life and/or ecology in the area. Each individual that submitted photographs was interviewed a second time to discuss the photographs. The photos and associated interviews provided valuable information about the broader context of the Baynes Sound area, including locally important places and issues.

In all but one case, interviews and photo interviews were audio recorded. Recordings were reviewed and transcribed. All interview transcripts and notes were analyzed and inductively coded in NVivo v.8 for themes, shared properties, and unique attributes.

We conducted a household survey to assess how residents of Baynes Sound responded to the perceptions of impacts on wellbeing identified in the interviews and subsequent qualitative analysis. The interview findings can be understood in their own right, in addition to providing the thematic categories around which the survey instrument was constructed, and are presented subsequently alongside the survey results. We focus on a series of survey questions that asked participants to rate their agreement/ disagreement with 13 statements about shellfish aquaculture. The 13 statements were based on the themes that emerged from the semistructured interview component. They do not, however, represent all of the issues recorded in the interviews and photo interviews, but rather a manageable number of statements that focused on issues for which the depth and breadth of opinions were not clear. Participants were asked to rate each statement on a 5 -point Likert-type scale where $1=$ strongly disagree, $2=$ disagree, $3=$ unsure, $4=$ agree, and $5=$ strongly agree.
The survey was conducted by mail in the communities that border the sound, namely Royston, Union Bay, Fanny Bay, Buckley Bay, Mud Bay, Deep Bay, and Bowser on Vancouver Island, and Denman Island on the east side of the sound. The study population was randomly sampled from a cleaned address list purchased from a direct mail and marketing company. We mailed 1139 surveys and made up to 4 contacts with each address according to a modified tailored design method (Dillman 2007). Despite our efforts to verify the addresses we used, some surveys were returned to us as undeliverable for various reasons. This diminished our survey population to 908 households. The survey had a response rate of $48 \%$ (439/908).

The survey sample was nearly evenly split between the genders: $44 \%$ female versus $51 \%$ male, with $4 \%$ not reporting, a proportion not significantly different from the 2010 census. Thirty-one percent of survey respondents lived on Denman Island, and 64\% identified as Vancouver Island residents, with 5\% not reporting. Respondents ranged in age from 27 to 92 years, with a mean age of 63, and had lived in the Baynes Sound area for an average of 21 years. Lower proportions of the survey sample reported annual household income in the highest (Can $\$ 80,000$ or more) and lowest $(<$ Can\$20,000) income categories than was reported in the 2010 census, with $21 \%$ of respondents declining to reveal income information. Respondents had overwhelmingly not ever been involved in aquaculture, i.e., $12 \%$ had been involved versus $87 \%$ had not been involved, with $1 \%$ not reporting; however, more than half reported having friends or family members who had worked in the industry, i.e., $55 \%$ versus $44 \%$, with $1 \%$ not reporting. None of these factors were statistically significant explanatory variables for the attitudes about shellfish aquaculture discussed subsequently. The test statistics used were t test for gender, island of residence, industry involvement, and friend/family industry involvement; and Spearman's correlation for income, age, and years of residence.

\section{RESULTS}

Results demonstrate that aquaculture affects individuals and communities along multiple pathways or dimensions that we have termed environment, economy, and experience. Each dimension is populated by a suite of themes (Table 1). Perceptions and opinions within each of the themes were variable: some themes were viewed largely positively, some were viewed largely negatively, and others engendered mixed responses. The interviews and survey also documented a sense of uncertainty common to perceptions of all three dimensions, highlighting fears of the unknown or unknowable, and often related to phenomena that were both hidden from sight and undocumented by scientific research.

\section{Environment}

Residents of the Baynes Sound area are attuned to the scenes, systems, and species of the landscape in which they live. When the ecological landscape changes, they interpret and assess those changes, including those perceived to arise from shellfish aquaculture, based on norms, individual values, and beliefs. Interviewees discussed a range of environmental themes such as water quality, wildlife, beach ecology, ocean bottom, and carrying capacity. They discussed the perceived environmental impacts of shellfish aquaculture in terms of how those impacts affected both ecosystem structure, such as naturalness, appearance, and other 
Table 1. Perceived effects of shellfish aquaculture identified by Baynes Sound interviewees.

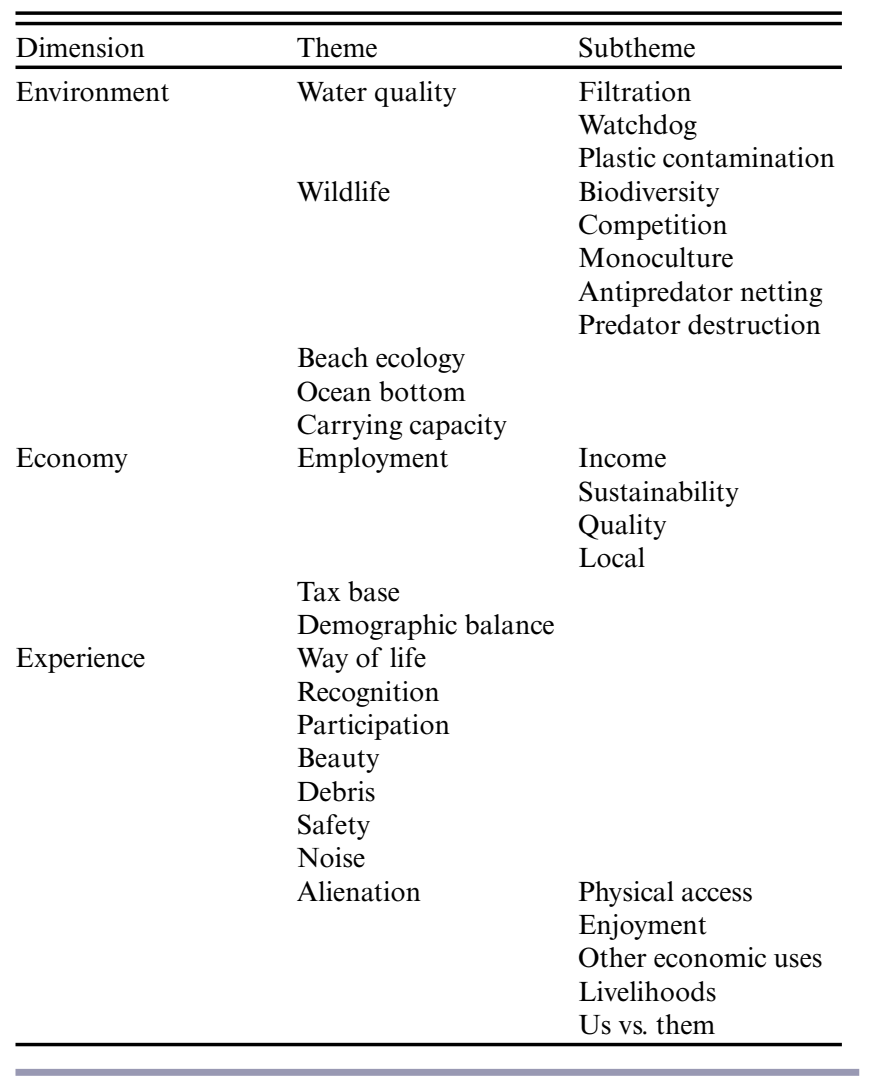

aesthetic changes, and ecosystem function, including feeding, recruitment, and other important processes. Survey respondents expressed largely negative and uncertain attitudes about shellfish aquaculture's effects on the environment (Table 2, statements $1-3)$.

Interviewees talked a good deal about water quality. Several industry and nonindustry interviewees shared concerns about the effects that plastics used in aquaculture have on the water chemistry and quality of the sound. Some interviewees pointed out that, like their wild counterparts, bivalves in aquaculture feed and grow by filtering and consuming small planktonic creatures that occur naturally in Baynes Sound. They noted that this filterfeeding mechanism cleans the sound's water by also removing other particulates.

\section{Oysters grow here on their own. You don't have to add anything to have them grow. So environmentally, they're keeping the water clean by filtering it. That's what they do. You are not adding anything to the environment in order for them to grow. So I think they are very important to keeping our waters clean. (Industry interviewee)}

More than half of the survey respondents $(56 \%)$ were uncertain about a statement that shellfish clean the water, whereas $24 \%$ disagreed or strongly disagreed with the statement and $20 \%$ agreed or strongly agreed that they do clean the water (Table 2, statement 2). In addition to effects like water filtration that result from the behavior of the shellfish themselves, interviewees perceived effects that arose from the activities of the industry as a whole. Some interviewees noted that shellfish aquaculture activities require exceptionally clean water to grow a product that is safe for human consumption, and they felt this vested interest in high water quality made the shellfish industry a steward or watchdog of the environment. They claimed that the long-term water quality of the sound depends on the shellfish industry.

I think that they [industry members] are in touch with the cleanliness, you know they're very connected to the ocean. And they could be really good advocates and speak up for that. And I think it is great that you know they are filters those shellfish and I like to think of them filtering away. So I actually, I mean, I think the shellfish industry really can be an integral part of how we protect our clean water environment, and I think they are. (Nonindustry interviewee)

Interviewees also noted a variety of effects on wildlife. These effects touched on subthemes of biodiversity, species competition, monocultures, and predator interactions. Interviewees involved in the aquaculture industry pointed out that aquaculture gear can enhance the abundance and diversity of other species in the waters of Baynes Sound and on area beaches by providing habitat and protection. Other interviewees questioned what happens when naturally occurring species and aquaculture overlap. There was a perception among a few nonindustry interviewees that by adding clams to beaches and covering them with nets to protect them from predation, shellfish aquaculture creates a monoculture. According to many nonindustry interviewees, the antipredator nets are contributing to native species loss because they destroy critical habitat for migratory birds and other animals. Some interviewees claimed that declines in some predator species like moon snails (Euspira lewisii), crabs (Cancer sp.), and sea stars (Pisaster sp.) have resulted from farmers physically removing them from leases and often destroying them to prevent loss of stocked species.

Other modifications to beaches, including the removal of large rocks from beach tenures, realignment of stream channels to direct freshwater away from leases, driving on the beach, and covering tenures with netting, were suggested by interviewees as detrimental to beach ecology and wildlife usage of beaches. Of particular concern were negative effects on salmon (Oncorhynchus sp.) and birds. Fifty-eight percent of survey respondents disagreed or strongly disagreed with a statement that shellfish aquaculture activities do not impact beach ecology, whereas 29\% were uncertain and only $13 \%$ agreed or strongly agreed (Table 2, statement 3).

Yeah, I mean like, beach alteration, which would include driving on the beach, and you know it looks to me like they've gone in with tractors or they floated ... they've moved big rocks around to create an area they can drive on, and that's a lot of alteration for something that's so delicate. (Nonindustry interviewee)

Many interviewees speculated about the occurrences and effects of the changes shellfish farming may be causing out of sight: in the water column or on the ocean bottom. They were concerned that certain aquaculture behaviors, particularly cleaning gear in 
Table 2. Survey responses to value statements ${ }^{\dagger}$ about perceived effects of shellfish aquaculture as the percentage of respondents in each response category. $\mathrm{N}=$ number of respondents who provided an answer to the statement. Possible responses were $\mathrm{SD}=$ strongly disagree; $\mathrm{D}=$ disagree; $\mathrm{U}=$ uncertain; $\mathrm{A}=$ agree; $\mathrm{SA}=$ strongly agree.

\begin{tabular}{|c|c|c|c|c|c|c|c|}
\hline No. & Survey Statement & $\mathrm{N}$ & SD & $\mathrm{D}$ & $\mathrm{U}$ & A & SA \\
\hline & Environment Dimension & & & & & & \\
\hline 1 & $\begin{array}{l}\text { I am concerned that floating shellfish tenures are causing pollution and changes } \\
\text { on the ocean bottom. }\end{array}$ & 417 & 4 & 17 & 33 & 24 & 23 \\
\hline 2 & The shellfish growing on farms clean the waters of Baynes Sound. & 411 & 9 & 15 & 56 & 16 & 4 \\
\hline 3 & $\begin{array}{l}\text { Shellfish aquaculture activities do not have important impacts on beach ecology. } \\
\text { Economy Dimension }\end{array}$ & 421 & 30 & 28 & 29 & 10 & 3 \\
\hline 4 & Shellfish aquaculture provides sustainable jobs. & 421 & 3 & 4 & 20 & 56 & 18 \\
\hline 5 & $\begin{array}{l}\text { The shellfish aquaculture industry should try to attract more tourists to boost the } \\
\text { local tourism economy. }\end{array}$ & 408 & 7 & 24 & 34 & 28 & 8 \\
\hline 6 & My town does not benefit economically from shellfish farming. & 415 & 15 & 41 & 27 & 11 & 7 \\
\hline 7 & $\begin{array}{l}\text { I don't think the local jobs in shellfish aquaculture are filled by local people. } \\
\text { Experience Dimension }\end{array}$ & 415 & 7 & 40 & 36 & 13 & 4 \\
\hline 8 & $\begin{array}{l}\text { I am proud that oysters grown on shellfish farms in Baynes Sound are on menus } \\
\text { across North America. }\end{array}$ & 416 & 4 & 6 & 16 & 40 & 33 \\
\hline 9 & Shellfish farming spoils the beauty of Baynes Sound. & 417 & 12 & 28 & 18 & 28 & 14 \\
\hline 10 & The presence of aquaculture gear reduces my enjoyment of the beach. & 423 & 10 & 28 & 10 & 26 & 25 \\
\hline 11 & Residents should accept noise from shellfish leases as a part of life here. & 418 & 22 & 28 & 17 & 28 & 6 \\
\hline 12 & $\begin{array}{l}\text { Seeing debris from shellfish farms washed up on the shoreline diminishes my } \\
\text { opinion of the industry. } \\
\text { Overall }\end{array}$ & 416 & 3 & 11 & 10 & 35 & 41 \\
\hline 13 & There should be more shellfish aquaculture in Baynes Sound. & 416 & 33 & 28 & 27 & 9 & 2 \\
\hline
\end{tabular}

the water at deep-water shellfish farms, have detrimental impacts on Baynes Sound ecology and questioned the potential effects of accumulated shellfish waste, shell material, and detritus on underlying sediments and water quality. Survey respondents were also concerned about bottom changes, but a large proportion $(33 \%)$ felt uncertain about the effects of deep-water tenures on the ocean bottom (Table 2, statement 1).

Many interviewees who were not affiliated with the industry suggested that the Baynes Sound shellfish industry is expanding. They were concerned that expansion would eclipse the carrying capacity of the sound and negatively affect ecosystem dynamics including the native food web (Fig. 2). Survey respondents were largely not in favor of or were uncertain about more shellfish aquaculture in the sound (Table 2, statement 13). Industry interviewees did not share the concerns about the sound's carrying capacity.

\section{Economy}

Local economic activity was a priority for Baynes Sound interviewees. Several interviewees pointed out that the area requires a local tax base and that the local aquaculture industry contributes a good deal to area communities. More than half of the survey respondents indicated they thought their town benefited economically from shellfish aquaculture, whereas $27 \%$ were uncertain about it and $18 \%$ indicated that their town did not benefit economically (Table 2, statement 6).

You have to understand too, that if we didn' have logging, if we didn't have oysters, if we didn't have shellfish, if we didn't have all these things, who's going to pay for what?
You've got to have a balance here. You've got to take the good with the bad. And hopefully make the bad better, and maybe the good, you can say well okay you can relax on this a little bit or something like that. (Nonindustry interviewee)

Fig. 2. "Concern" photo representing the carrying capacity theme: "Is there enough food? And if there is enough food, is there a limit to that? And if there is a limit to that, what are the consequences of exceeding that limit? Not just to the aquaculture industry, but also to the local populations of animals that depend on that food?" (Nonindustry interviewee)

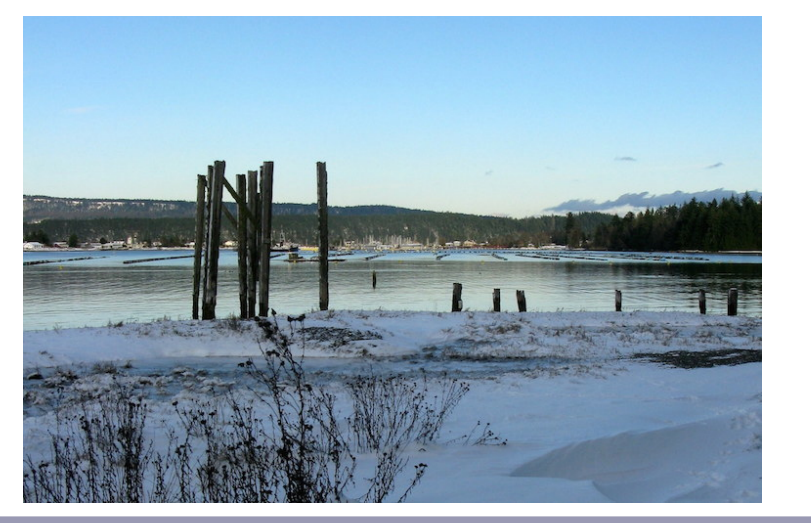


Interviewees from the industry pointed out that shellfish aquaculture provides steady income.

\begin{abstract}
And I know lots of people that have raised their whole families and everything on it. You know, over the years. And built nice houses. So I think in that manner it's a good thing for the sound and the valley and that. (Industry interviewee)
\end{abstract}

Many other interviewees also valued shellfish aquaculture as a source of income but pointed out that gains the industry provides in the form of jobs in the natural resources sector and to the local economy generally should be balanced against possible detriments. They were cautious about the level and kind of economic activity occurring locally, concerned that the quiet and serene character of the area should not be lost. Many interviewees valued economic activity that would be locally owned, employ local people, be sustainable, provide sustainable jobs, and forge connections to other local businesses and the rest of the community. Perceptions varied about the shellfish aquaculture industry's ability to meet these criteria (Fig. 3).

Fig. 3. "Like" photo representing the local economic activity theme: "Okay, this picture we have a schoolhouse in the background. We have people working with scallops. And we have the mountains in the back. So the reason I like this one is because it's sort of showing a whole community involvement. You have the children growing up learning, getting to watch sustainable activities around you. And right in the middle of beautiful nature." (Industry interviewee)

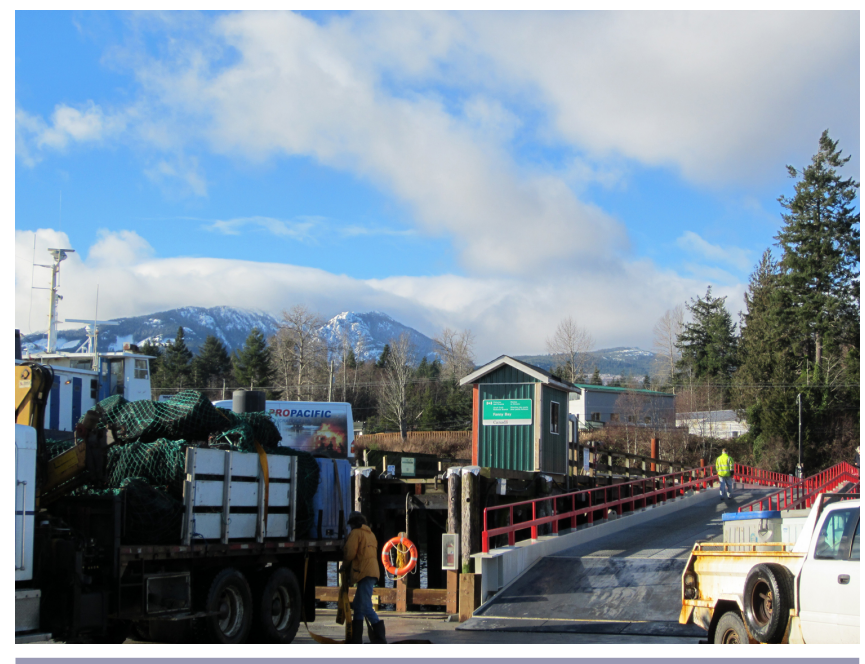

Jobs in the Baynes Sound area have historically been resource based, but those traditional jobs are in decline. Tourism and recreation are on the rise. More than a third of survey respondents expressed uncertainty about whether the aquaculture industry should try to encourage tourism, with the remaining respondents nearly evenly split between agreement and disagreement, i.e., disagree + strongly disagree $=31 \%$ versus agree + strongly agree $=36 \%$ (Table 2, statement 5). Nearly three-fourths of survey respondents agreed that shellfish aquaculture provides sustainable jobs, i.e., agree + strongly agree $=74 \%$ (Table 2 , statement 4), and industry interviewees questioned the sustainability of other new employment opportunities compared to shellfish aquaculture.

What kept this small community going was a resourcebased industry - logging and fishing. It's not the same anymore. And so what do you have as a foundation in a community to provide good jobs for people? Is it tourism, which is often, for the most part, it's minimum wage paying jobs for 6 months of the year? Is that what you define as sustainable? And so, is it a mine that comes in with a 10-year life span, that provides really good jobs for 10 years and then goes away? Long term, is that sustainable? (Industry interviewee)

Although they agree that shellfish aquaculture jobs themselves may be sustainable, many interviewees, including members of the industry, questioned whether aquaculture jobs could sustain a worker over an extended time. Some interviewees perceived aquaculture jobs as low quality. These concerns underscored the importance of job quality not just job numbers.

Some of the jobs we have, like for instance harvesting oysters on the beach, it's not a job that you're probably going to think: I'm going to make a career out of this. So you have people that come, theyneed work - 3 months, 4 months, and then they move on. And some people, it motivates them to maybe do something with their life because they realize - some people - that if they don't do something with their life, they're going to be relegated to doing work like this the rest of their life. (Industry interviewee)

In addition to questions about job quality, interviewees questioned whether Baynes Sound residents were filling the aquaculture jobs in the sound. Few interviewees, especially those who live on Denman Island, believed that shellfish aquaculture workers actually lived in their local community. The survey revealed that most respondents either thought that aquaculture jobs employed local people, i.e., disagree + strongly disagree $=$ $47 \%$, or they were uncertain about the issue $(36 \%$; Table 2 , statement 7). Industry interviewees pointed out that the rising cost of living in the area makes it difficult for individuals and families to support themselves locally on industry wages. They cautioned that if local real estate prices continue to rise, the industry will likely have to draw workers from the larger, more affordable nearby towns.

Interviewees' discussions of industry jobs and related issues included broader concerns about the struggles young people and families face in their communities and the roles of younger residents in the local economy. Interviewees reported that young residents struggle to stay in the area for a variety of reasons such as limited local employment options and school closures.

I mean, once the schools close down, they don't get reopened. People move away; they don't move there and say, well, I'm going to move there; I hope the school opens again. The people with the kids stop living there and that's deadly. Like it just would be ... I would cry, like it would have such wide-reaching effects socially and economically, because you need those people in their twenties and thirties. (Nonindustry interviewee) 
Perceptions about the shellfish aquaculture industry's ability to contribute to the retention of younger residents varied according to an interviewee's perceptions about job quality, pay rate, and other factors.

\section{Experience}

The experience dimension refers to effects that are neither strictly environmental nor economic, but that alter Baynes Sound interviewees' expectations of their lived experience. Some of these expectations had to do with experiences of the physical surroundings, focusing on themes such as debris, views, and access. Others centered on livelihood, social, and psychological experiences. For many interviewees not affiliated with the industry, lived experience related to an aesthetic that includes ruggedness, abundant wildlife, and open space and was negatively affected by shellfish aquaculture. Themes related to lived experience received strongly directional (Table 2, statements 8 and 12) as well as mixed and bimodal responses in the survey (Table 2, statements 9-11).

Many of the themes of lived experience were related to connection to place. Interviewees recognized that shellfish farming is a way of life in Baynes Sound that connects to local history and identity. Clams and oysters were considered an indelible part of the landscape.

What grows on Denman? Shellfish. And Douglas fir. And deer. And people. And, you know, you can grow a bunch of other things, but boy, if there are specialty products that people can use from the Island ... look at the middens! (Nonindustry interviewee)

Some interviewees expressed pride that people in places near and far know the shellfish, most notably the oysters, produced in the local waters. They felt that through this recognition the shellfish aquaculture industry puts Baynes Sound on the map. Nearly three-fourths of survey respondents agreed or strongly agreed that they were proud that locally grown shellfish were on menus across the continent (Table 2, statement 8). A few interviewees also noted instances of community participation whereby the shellfish industry or individual farmers contributed products to local events, stressing the generosity of these connections.

They get good vibes out to the public in the way of recipes and things like that. They donate so much, not just to our group, but to other groups. And I think they're excellent that way, very, very good. You cannot say anything bad against them. They're great. (Nonindustry interviewee)

Interviewees described Baynes Sound as a beautiful place citing the natural attributes of the area such as lush forests, open water, and a snow-capped mountain backdrop. They described aspects of it as "pristine." For some of these individuals, shellfish aquaculture installations reduce the beauty of Baynes Sound by making it less natural and threatening its pristine qualities. Nearly equal proportions of survey respondents agreed that shellfish farming spoils the beauty of the area as disagreed with the statement (Table 2, statement 9). Industry interviewees also decried the idea of filling the sound with the rafts and gear of deep-water leases, but some questioned whether a right to a certain view is inherent in property ownership and suggested that some unobstructed views must be traded off for the economy.
So it's that ... trying to find that balance between economic activity - sustainable economic activity - and viewscapes and how much right to a viewscape does one have when they buy a piece of waterfront. There's an inherent belief that with that property comes this unobstructed view, but is that true, or is it just a perception? (Industry interviewee)

A few interviewees noted the noise that shellfish farming can generate, including vehicle noise, talking, swearing, and music on leases, which can carry across the water and foreshore. They claimed that increased mechanization of deep-water shellfish farming to raise and lower baskets, power-wash equipment, and perform other tasks contributed additional noise. As many survey respondents agreed with a statement that residents should accept noise from the leases as disagreed with it $(28 \%)$; however, $22 \%$ of respondents strongly disagreed with the statement, whereas only $6 \%$ strongly agreed with it (Table 2 , statement 11 ). Some industry interviewees claimed that they can only do so much to accommodate noise complaints from residents and are not doing anything that they have not been doing for the past 20-30 years.

Many interviewees noted the debris or garbage from aquaculture that ends up on area beaches, especially during stormy conditions. Although a large proportion of survey respondents agreed that aquaculture debris diminished their opinion of the industry $(35 \%)$, an even larger proportion strongly agreed $(41 \%$; Table 2 , statement 12).

There wouldn't be the same opposition to the industry, I don't think, if that was one of the things they paid attention to. Because it really focuses the mind on the industry when you go along the beach and you can't walk along the beach any day without finding masses of debris from the industry. (Nonindustry interviewee)

Although dislodged shellfish aquaculture equipment can end up as debris, some interviewees regarded some equipment that remains in place as hazards to human safety. A general concern was that improperly marked and maintained equipment, metal, and netting could result in tragic accidents. Industry interviewees acknowledged the debris problem, though some downplayed it. One farmer pointed out a connection between debris and the thin economic margins of the smaller leaseholders: small leaseholders cannot spare the work hours needed to collect debris, and employees of larger leaseholders and processing houses collect debris only when directed to do so.

I see the pollution, the garbage, the debris continuing until we can get the economics sorted out. I see it. I fear it. It disgusts me. But I don't see a solution until we can fix the economics of it. That's what I believe. I believe there's many people ... they all live around here; nobody likes to see garbage. But who's going to do something about it? Sorry, you're going to put me in tears just thinking about it. (Industry interviewee)

Many themes discussed by interviewees within the experience dimension touched on a larger theme of alienation. In addition to the issues related to views, debris, and noise that tend to alienate people from their preferred state of nature, additional issues related to shellfish aquaculture were perceived as wedges between the community and surroundings. Separation from nature for 
people who highly value their experiences in nature, for example, was seen as detrimental. Nearly as many survey respondents agreed with a statement that the presence of aquaculture gear reduces enjoyment of the beach as disagreed with it; however, $25 \%$ of respondents strongly agreed that it reduces enjoyment, whereas $10 \%$ strongly disagreed (Table 2, statement 10 ). In addition, interviewees pointed out that aquaculture installations, such as antipredator netting, physically alienate people by limiting public access or use of the foreshore and other areas.

You know I think the public - all the residents that live on the island or anywhere that's near the ocean - have a right to enjoy, and when it's covered by netting and shellfish tenures that go the whole length of Baynes Sound, that makes it very difficult for the public that have a right to enjoy the beach. (Nonindustry interviewee)

Some interviewees suggested that the current extent and possible expansion of the shellfish aquaculture industry potentially alienates other economic uses and values from Baynes Sound. Although making it clear that they do not want to see a sound full of other commercial activities, these interviewees were concerned that there should be a variety of activities. A few interviewees suggested that the intensification of the industry had alienated some residents from shellfish farming, thereby contributing to the alienation of livelihoods from the foreshore and waters of the sound. Other interviewees noted that the economic gains that do accrue from shellfish aquaculture do not have the same impact in all of the Baynes Sound communities. According to one interviewee, even though she suspects it is the top income-generating industry on Denman Island, because farmers and workers do not shop on the island, the money that is generated on the island's foreshore does not stay in the community.

Another form of alienation stems from interviewees' perception that there is limited interaction between farmers/growers and the rest of the community. They suggested that community members feel alienated from an industry that they can see plainly on the foreshore and water but know very little about. As a point of comparison, a few interviewees noted that they know local agricultural farmers and enjoy buying products directly from them at area farmers markets.

So you know, I know people who have had leases in the past, but it does seem, as I said and this is one of my concerns, that it doesn't feel like it's an us thing, you know, it's a them thing. And in such a little place that doesn't work very well. You know, if they were people we knew, and if we could go once a week or we could go to the general store and buy the stuff that was harvested that day ... It's like the community is this weave, and then there's this fabric that's not woven into it. (Nonindustry interviewee)

\section{DISCUSSION}

Interview findings and survey results demonstrate that perceptions of the effects of an adaptation like aquaculture on social-ecological conditions have important subjective components that vary from highly positive to highly negative across environmental, economic, and experience dimensions. Perceptions tended to depend in part on an interviewee's position within or outside of the aquaculture industry. Industry interviewees tended to focus on the environmental and economic benefits while acknowledging some of the concerns regarding the environment and lived experience. Nonindustry interviewees typically expressed questions and concerns about environmental effects while underscoring economic benefits and focusing on negative effects on experience. Most survey participants felt that shellfish aquaculture had positive economic effects, and they felt negatively or uncertain about its effects on the environment. Their perceptions of the effects on lived experience were more variable: positive, negative, and mixed/bimodal responses.

These results echo the findings of other studies of public perceptions of aquaculture in other areas. A survey of residents of coastal areas of South Australia found concerns about shellfish aquaculture's environmental impacts and uncertainty regarding its environmental benefits, including effects on water quality (Mazur and Curtis 2008). A survey of attitudes toward salmon farming among the general public in Scottish coastal areas showed that employment and livelihood benefits were considered the most important socioeconomic benefits, and that minimizing pollution/water quality impacts and detriments to wild stocks were more important than minimizing visual and landscape impacts (Whitmarsh and Palmieri 2009). The comparative importance of impacts remains unexplored in British Columbia.

Uncertainty cut across all dimensions and was at the core of many interviewees' concerns and feelings of alienation. The greatest uncertainty was related to the environment and economy dimensions, whereas the experience dimension elicited less uncertainty (Table 2). Uncertainty represented fears of the loss of the natural ecological community and led to feelings of powerlessness, disconnection, and anxiety. This uncertainty was rooted in a perception that proper studies are not being undertaken to examine issues of concern. Interviewees reported a dearth of information about the industry and its effects, positive or negative, and no sense of where to turn to find such information. As a result, they were largely ignorant of planning related to shellfish aquaculture. Many who were not involved in the industry seemed to want to support local aquaculture more, but limited information left them with uncertain attitudes and feelings of distrust. Although criticisms of shellfish aquaculture may never disappear, attitudes toward the industry could be improved by establishing communication channels between the industry and the community. Efforts like extending local farmers markets to include shellfish farmers could be an important tool for improving relations and communication. Participation by local shellfish farms in ecolabeling under the Global Aquaculture Alliance Best Aquaculture Practices, which includes standards for community relations, could also improve attitudes.

It is worth noting some of the methodological implications of our study. For example, because the qualitative data collection focused on the perceptions of those interviewed, the resulting data on their own are not necessarily representative. However, by testing them in the subsequent quantitative survey, the resulting combination of interview and survey data provides a window into the relationship between aquaculture and place. We also note that, because it is based on perceptions, the analysis that emerges may not accommodate the "actual" effects of shellfish aquaculture. That said, we would argue that even in cases in which perceptions 
may not be accurate, they can usefully illuminate areas of uncertainty or ignorance for improved communication and transparency.

Our multimethod approach was a useful way to focus on the preferences for social-ecological conditions of both industry and nonindustry residents. Preferences for social-ecological conditions are based in part on how people value and perceive ecosystem goods and services that promote well-being. Adaptations, like aquaculture or other new uses of resources or sea space as responses to changing circumstances, can enhance or diminish social-ecological conditions, thereby affecting the flow of goods and services and the well-being within an SES. Aquaculture may enhance material well-being through the economic benefits of enhanced provisioning ecosystem services, but other components of well-being may decline as a result of negative effects on other ecosystem services (Outeiro and Villasante 2013). By engaging with values, preferences, and perceptions rather than simply objective material needs and economic imperatives, our approach explored the normative and subjective dimensions of the trade-offs inherent in shellfish aquaculture and, by extension, other activities in marine/coastal SESs (McGregor 2008, Armitage et al. 2012). The resulting gains and losses were differentially experienced across the social subsystem (Coulthard 2012) as demonstrated by the variability in the documented perceptions.

As an analytical lens, well-being makes a valuable addition to attempts like ours to understand the dynamics of coastal communities by providing a framework for understanding what matters to individuals and communities (Weerantunge et al. 2014). By understanding what matters and contributes to the subjective sense of well-being among diverse stakeholders, we can begin to understand how the benefits and losses of an adaptation are distributed within a society and how adaptations are or are not socially sustainable (Coulthard 2012, Outeiro and Villasante 2013). Our definition of well-being is three-dimensional, incorporating aspects that are material, relational, and subjective (Armitage et al. 2012). Interviewees' perceptions were also multidimensional with significant overlap with the dimensions of well-being. Interviewees expressed material concerns relating to the environment and the economy including water quality, jobs/ income, and local tax base. They also expressed relational concerns including the demographic balance of their communities as well as issues of connection and alienation between the aquaculture industry and the rest of the community. Finally, many of the themes of the lived experience dimension intertwined objective concerns with subjectivity such as beauty and pride.

Previous work has suggested that public attitudes toward aquaculture, specifically salmon farming, are related to how people weigh the economic benefits against the environmental detriments (Whitmarsh and Palmieri 2009). We found that perceptions of the effects of shellfish aquaculture were not a simple binary of jobs versus environment. Job creation for younger residents and a tax base to support local infrastructure were important to interviewees, but these individuals were also concerned with job quality, sustainability, and demographic balance. As a group, interviewees were also deeply connected to the environment and critical of any activity that could negatively affect ecological function. They regarded a healthy ecosystem as fundamental to the Baynes Sound experience, an experience rooted in the interviewees' subjective placement of themselves in the landscape. As such, although the objective economic and environmental dimensions made important contributions, wellbeing was rooted in the subjective translations of objective measures of the experience dimension.

Our approach and results have relevance for coastal policy making and planning initiatives. Divergences among residents' perceptions, images of nature, and senses of well-being like those we identified can translate into different opinions on efforts to implement adaptations to coastal change, coastal planning, and decision making (Buijs 2009, Whitmarsh and Palmieri 2009, Trimble and Johnson 2013). By moving beyond the economy versus environment debate, the well-being approach is a more inclusive means of deciphering the consequences of policies and plans based on local preferences and values (May 2007). Generally, in fisheries policy, there has been a lack of attention to the differential impacts that management measures have on the well-being of all members of a fishing society (Coulthard et al. 2011). We find the same to be true of aquaculture communities: the effects of industry and associated policy decisions are perceived and experienced unevenly in the surrounding society, producing "winners" and "losers" (Joyce and Canessa 2009, Outeiro and Villasante 2013, Silver 3013). Unpacking the multiple dimensions of the effects of shellfish aquaculture from a wellbeing perspective provides a basis for understanding the factors that influence responses to policy and governance and the values that guide decision making in the first place.

This work also has clear implications for ongoing aquaculture policy and management efforts in British Columbia and beyond. Under the Oceans Act, DFO is moving toward an integrated management model that includes consideration of the social consequences of management decisions and planning processes. Such ecosystem-based management approaches need to adopt a nuanced understanding of social dynamics and other insights from social-ecological research of the kind we have presented (Benessaiah and Sengupta 2014). Specific efforts to enhance and advance environmentally and socially sustainable aquaculture in Canada under the National Aquaculture Strategic Action Plan Initiative call for enhancing "social license" by improving governance and oversight. A perceived lack of sufficient oversight, enforcement, and penalties for violations of leasemanagement plans generated feelings of uncertainty and negative attitudes toward the industry among our interviewees. This finding resonates with results from focus groups conducted by DFO wherein participants expressed concern that aquaculture is under no one's control and that without better control the industry is in the hands of those who are driven by profits, not health or environmental safety (DFO 2005). By focusing attempts to increase the social license of the aquaculture industry on transparent communication and community engagement, the initiative tacitly acknowledges the uncertainty and lack of information described by our study participants. Our results point to several issues and community concerns that could be addressed through enhanced communication and engagement.

\section{CONCLUSION}

We examined the effects of shellfish aquaculture in Baynes Sound by focusing on preferences for social-ecological conditions and the ways in which local conditions are perceived to be enhanced 
or diminished by adaptive alternative industries like aquaculture. By taking a well-being approach, our study points out that perceived environmental risks or economic opportunities are not all that matter to communities living adjacent to shellfish aquaculture installations. As the aquaculture industry continues to grow, expanding into new geographies, species, and technologies, there will no doubt be new conflicting perceptions to address. For example, integrated multitrophic aquaculture and closed-containment facilities that attempt to address the environmental risks inherent in mostly finfish aquaculture suggest that addressing aquaculture's environmental issues addresses the entire aquaculture issue. Our findings suggest otherwise: aquaculture decision making and development would benefit from taking a social-ecological perspective that considers wellbeing. Alongside objective measures of costs and benefits, distinctly subjective perceptions will dictate the success or failure of new or expanding resource uses such as aquaculture. We suggest that conflicts around aquaculture management and governance can be traced to an incompatibility among people's subjective perceptions of well-being. Recognition of the multidimensionality and subjectivity of well-being and its connection to social license, through the broader integration of local stakeholder and community perceptions into aquaculture policy and governance, could aid in achieving sustainable aquaculture and other adaptions in changing coastal communities.

Responses to this article can be read online at: http://www.ecologyandsociety.org/issues/responses. php/7319

\begin{abstract}
Acknowledgments:
The authors gratefully acknowledge and thank the interviewees and survey participants for sharing their time, knowledge, insights, and opinions. The authors also thank Sarah Dudas, Brian Kingzett, and Bill Pennell for providing valuable guidance during the project and Tegan Padgett for assistance administering the survey. Funding and support for this work were received from VIU Institute for Coastal Research and the Natural Sciences and Engineering Research Council of Canada (NSERC) strategic Canadian Integrated Multi-Trophic Aquaculture Network (CIMTAN) in collaboration with its partners, Fisheries and Oceans Canada, the University of New Brunswick, Cooke Aquaculture Inc., Kyuquot SEAfoods Ltd., and Marine Harvest Canada Ltd.
\end{abstract}

\section{LITERATURE CITED}

Armitage, D., C. Béné, A. T. Charles, D. Johnson, and E. H. Allison. 2012. The interplay of well-being and resilience in applying a social-ecological perspective. Ecology and Society 17 (4): 15. http://dx.doi.org/10.5751/ES-04940-170415

Barbier, E. B., S. D. Hacker, C. Kennedy, E. W. Koch, A. C. Stier, and B. R. Silliman. 2011. The value of estuarine and coastal ecosystem services. Ecological Monographs 81:169-193. http://dx. doi.org/10.1890/10-1510.1
Benessaiah, K., and R. Sengupta. 2014. How is shrimp aquaculture transforming coastal livelihoods and lagoons in Estero Real, Nicaragua? The need to integrate social-ecological research and ecosystem-based approaches. Environmental Management 54:162-179. http://dx.doi.org/10.1007/s00267-014-0295$\underline{\mathrm{X}}$

British Columbia Ministry of Sustainable Resource Management (BCMSRM). 2002. The Baynes Sound coastal plan for shellfish aquaculture. BCMSRM, Victoria, British Columbia, Canada. [online] URL: http://www.for.gov.bc.ca/tasb/SLRP/marine/south island/ baynes/docs/Baynes Plan Dec19 2002.pdf

Buijs, A. E. 2009. Lay people's images of nature: comprehensive frameworks of values, beliefs, and value orientations. Society \& Natural Resources 22:417-432. http://dx.doi.org/10.1080/08941920801901335

Byron, C., D. Bengtson, B. Costa-Pierce, and J. Calanni. 2011. Integrating science into management: ecological carrying capacity of bivalve shellfish aquaculture. Marine Policy 35:363-370. http://dx.doi.org/10.1016/j.marpol.2010.10.016

Carswell, B., S. Cheesman, and J. Anderson. 2006. The use of spatial analysis for the environmental assessment of shellfish aquaculture in Baynes Sound, Vancouver Island, British Columbia, Canada. Aquaculture 253:408-414. http://dx.doi. org/10.1016/j.aquaculture.2005.08.024

Comox Valley Regional Growth Strategy (CVRGS). 2009. Understanding our choices. CVRGS, Courtenay, British Columbia, Canada.

Coulthard, S. 2012. Can we be both resilient and well, and what choices do people have? Incorporating agency into the resilience debate from a fisheries perspective. Ecology and Society 17(1): 4. http://dx.doi.org/10.5751/ES-04483-170104

Coulthard, S., D. Johnson, and J. A. McGregor. 2011. Poverty, sustainability and human wellbeing: a social wellbeing approach to the global fisheries crisis. Global Environmental Change 21:453-463. http://dx.doi.org/10.1016/j.gloenvcha.2011.01.003

Crain, C. M., B. S. Halpern, M. W. Beck, and C. V. Kappel. 2009. Understanding and managing human threats to the coastal marine environment. Annals of the New York Academy of Sciences 1162:39-62. http://dx.doi.org/10.1111/j.1749-6632.2009.04496.x

Dillman, D. A. 2007. Mail and Internet surveys: the tailored design method. John Wiley and Sons, Hoboken, New Jersey, USA.

Fisheries and Oceans Canada (DFO). 2005. Qualitative research exploring Canadians' perceptions, attitudes and concerns towards aquaculture. DFO, Ottawa, Ontario, Canada. [online] URL: http://www.dfo-mpo.gc.ca/por-rop/focus-aquaculture-eng.htm

Fisheries and Oceans Canada (DFO). 2013. Socio-economic impact of aquaculture in Canada. DFO, Ottawa, Ontario, Canada. [online] URL: http://www.dfo-mpo.gc.ca/aquaculture/sectorsecteur/socio/index-eng.htm

Folke, C., S. R. Carpenter, B. Walker, M. Scheffer, T. Chapin, and J. Rockström. 2010. Resilience thinking: integrating resilience, adaptability and transformability. Ecology and Society 15(4): 20. [online] URL: http://www.ecologyandsociety.org/vol15/iss4/ art20/ 
Food and Aquaculture Organization of the United Nations (FAO), Fisheries and Aquaculture Department. 2014. The state of world fisheries and aquaculture. FAO, Rome, Italy.

Gibbs, M. T. 2009. Implementation barriers to establishing a sustainable coastal aquaculture sector. Marine Policy 33:83-89. http://dx.doi.org/10.1016/j.marpol.2008.04.004

Hamouda, L., K. W. Hipel, and D. M. Kilgour. 2004. Shellfish conflict in Baynes Sound: a strategic perspective. Environmental Management 34:474-486. http://dx.doi.org/10.1007/s00267-004-0227-2

Hoegh-Guldberg, O., and J. F. Bruno. 2010. The impact of climate change on the world's marine ecosystems. Science 328:1523-1528. http://dx.doi.org/10.1126/science.1189930

Joyce, A., and R. Canessa. 2009. Spatial and temporal changes in access rights to shellfish resources in British Columbia. Coastal Management 37:585-616. http://dx.doi.org/10.1080/08920750903097517

Joyce, A. L., and T. A. Satterfield. 2010. Shellfish aquaculture and First Nations' sovereignty: the quest for sustainable development in contested sea space. Natural Resources Forum 34:106-123. http://dx.doi.org/10.1111/j.1477-8947.2010.01297.x

May, D. 2007. Determinants of well-being. Memorial University of Newfoundland and Newfoundland and Labrador Statistics Agency, St. John's, Newfoundland and Labrador, Canada. [online] URL: http://www.communityaccounts.ca/communityaccounts/ onlinedata/pdf files/DeterminantsOfWellBeing-06.pdf

Mazur, N. A., and A. L. Curtis. 2006. Risk perceptions, aquaculture, and issues of trust: lessons from Australia. Society \& Natural Resources 19:791-808. http://dx.doi.org/10.1080/0894$\underline{1920600835551}$

Mazur, N. A., and A. L. Curtis. 2008. Understanding community perceptions of aquaculture: lessons from Australia. Aquaculture International 16:601-621. http://dx.doi.org/10.1007/s10499-008-9171-0

McGregor, J. A. 2008. Wellbeing, poverty and conflict. WeD Briefing Paper 1/08. Economic \& Social Research Council (ESRC) Research Group on Wellbeing in Developing Countries (WeD), University of Bath, Bath, UK.

Millennium Ecosystem Assessment (MEA). 2005. Ecosystems and human wellbeing: synthesis. Island, Washington, D.C., USA.

National Research Council (NRC). 2010. Ecosystem concepts for sustainable bivalve mariculture. National Academies, Washington, D.C., USA.

Olin, P. G., J. Smith, and R. Nabi. 2011. Regional review on status and trends in aquaculture development in North America: Canada and the United States of America-2010. FAO Fisheries and Aquaculture Circular No. 1061/2. FAO, Rome, Italy.

Outeiro, L., and S. Villasante. 2013. Linking salmon aquaculture synergies and trade-offs on ecosystem services to human wellbeing constituents. AMBIO 42:1022-1036. http://dx.doi. org/10.1007/s13280-013-0457-8

Pierce, J., and J. McKay. 2008. On community capitals as we see them through photovoice: Cowell oyster industry in South Australia. Australasian Journal of Environmental Management 15:159-168. http://dx.doi.org/10.1080/14486563.2008.9725198
Pinkerton, E., and J. Silver. 2011. Cadastralizing or coordinating the clam commons: can competing community and government visions of wild and farmed fisheries be reconciled? Marine Policy 35:63-72. http://dx.doi.org/10.1016/j.marpol.2010.08.002

Poloczanska, E. S., C. J. Brown, W. J. Sydeman, W. Kiessling, D. S. Schoeman, P. J. Moore, K. Brander, J. F. Bruno, L. B. Buckley, M. T. Burrows, C. M. Duarte, B. S. Halpern, J. Holding, C. V. Kappel, M. I. O'Connor, J. M. Pandolfi, C. Parmesan, F. Schwing, S. A. Thompson, and A. J. Richardson. 2013. Global imprint of climate change on marine life. Nature Climate Change 3:919-925. http://dx.doi.org/10.1038/nclimate1958

Quayle, D. B. 1988. Pacific oyster culture in British Columbia. Canadian Bulletin of Fisheries and Aquatic Sciences 218. Fisheries and Oceans Canada, Ottawa, Ontario, Canada.

Rudell, P. N. 2012. Human perceptions and attitudes regarding geoduck aquaculture in Puget Sound, Washington: a $Q$ methodology approach. Thesis. University of Washington, Seattle, Washington, USA.

Shumway, S. E., C. Davis, R. Downey, R. Karney, J. Kraeuter, J. Parsons, R. Rheault, and G. Wikfors. 2003. Shellfish aquaculture -in praise of sustainable economies and environments. World Aquaculture 34(4):15-17.

Silver, J. J. 2013. Neoliberalizing coastal space and subjects: on shellfish aquaculture projections, interventions and outcomes in British Columbia, Canada. Journal of Rural Studies 32:430-438. http://dx.doi.org/10.1016/j.jrurstud.2013.10.003

Silver, J. J. 2014. From fishing to farming: shellfish aquaculture expansion and complexities of ocean space on Canada's west coast. Applied Geography 54:110-117. http://dx.doi.org/10.1016/ j.apgeog.2014.07.013

Stroomer, C., and M. Wilson. 2013. British Columbia's fisheries and aquaculture sector. 2012 edition. BC Stats, Government of British Columbia, Victoria, British Columbia, Canada.

Tidwell, J. H., and G. L. Allen. 2001. Fish as food: aquaculture's contribution. EMBO Reports 2:958-963. http://dx.doi.org/10.1093/ embo-reports/kve236

Trimble, M., and D. Johnson. 2013. Artisanal fishing as an undesirable way of life? The implications for governance of fishers' wellbeing aspirations in coastal Uruguay and southeastern Brazil. Marine Policy 37:37-44. http://dx.doi. org/10.1016/j.marpol.2012.04.002

Weeratunge, N., C. Béné, R. Siriwardane, A. Charles, D. Johnson, E. H. Allison, P. K. Nayuk, and M. C. Badjeck. 2014. Small-scale fisheries through the wellbeing lens. Fish and Fisheries 15:255-279. http://dx.doi.org/10.1111/faf.12016

Whitmarsh, D., and M. G. Palmieri. 2009. Social acceptability of marine aquaculture: the use of survey-based methods for eliciting public and stakeholder preferences. Marine Policy 33:452-457. http://dx.doi.org/10.1016/j.marpol.2008.10.003

Worm, B., E. B. Barbier, N. Beaumont, J. E. Duffy, C. Folke, B. S. Halpern, J. B. C. Jackson, H. K. Lotze, F. Micheli, S. R. Palumbi, E. Sala, K. A. Selkoe, J. J. Stachowicz, and R. Wilson. 2006. Impacts of biodiversity loss on ocean ecosystem services. Science 314:787-790. http://dx.doi.org/10.1126/science.1132294 